\title{
Waste Fiber-Based Cellulose Supported Polymer Ligands for Toxic Metals Removal from Industrial Wastewater $^{+}$
}

\author{
Md Lutfor Rahman *, Choong Jian Fui, Tang Xin Ting, Mohd Sani Sarjadi, Sazmal E. Arshad \\ and Baba Musta \\ Faculty of Science and Nature Resources, University Sabah Malaysia, 88400 Kota Kinabalu, Malaysia; \\ jianfui@hotmail.com (C.J.F.); tangxinting_0917@hotmail.com (T.X.T.); msani@ums.edu.my (M.S.S.); \\ sazmal@ums.edu.my (S.E.A.); babamus@ums.edu.my (B.M.) \\ * Correspondence: lutfor73@gmail.com \\ + Presented at the First International Conference on “Green" Polymer Materials 2020, 5-25 November 2020; \\ Available online: https://cgpm2020.sciforum.net/.
}

Published: 4 November 2020

\begin{abstract}
Toxic metals pollution in the wastewater is a drastic situation hence a powerful and economical treatment technology is needed for the water purification. For that reason some pure cellulosic materials were extracted from waste fiber and further modification of the cellulose was performed by free radical grafting reaction resulting the poly (methyl acrylate)-grafted cellulose and poly(acrylonitrile)-grafted cellulose. Consequently, poly (hydroxamic acid) and poly (amidoxime) ligands were prepared from the grafted cellulose. The adsorption capacity $\left(\mathrm{q}_{\mathrm{e}}\right)$ of some toxic metals ions with the polymer ligands was found excellent, e.g. copper capacity $\left(\mathrm{q}_{\mathrm{e}}\right)$ for poly (hydroxamic acid) is $375 \mathrm{mg} / \mathrm{g}$ whereas qe for poly (amidoxime) ligand is $355 \mathrm{mg} / \mathrm{g}$ at $\mathrm{pH}$ 6. Other metal ions (iron, chromium, cobalt, zinc and nickel) show significance binding properties at $\mathrm{pH} 6$. The Langmuir and Freundlich isotherm studies were also performed and Freundlich isotherm model showed good correlation coefficients for all metal ions, indicating that multiple-layers adsorption occurred. The both polymeric ligands showed outstanding toxic metals removal magnitude, up to $90-98 \%$ of toxic metal ions can be removed from industrial wastewater.
\end{abstract}

Keywords: adsorption; waste cellulose; poly (hydroxamic acid); poly (amidoxime); wastewater

\section{Introduction}

Undoubtedly, water is essential for all living things, therefore, water has a vital role to the environment for the existence of life. However, water quality is affected due to the urbanization, industrialization and agricultural activities etc. Many types of water pollution, existence of toxic metals in the wastewater are one of the biggest causes of water contamination [1]. Non-biodegradable toxic metals are generated and present in the factory sewage and waste from factory processes such as electroplating, electrolysis depositions, milling, and metal coatings etc. [2]. The detrimental health effects arises due to the hazardous toxic metals consequently various conventional methods or treatments have been useful for safe water and environment. For example, adsorption [3], precipitation [4], coagulation [5], reverse osmosis [6], and membrane filtration [7] have been conventionally used in industry processes. Among these conventional methods, adsorption has been proven to be a very promising and cost-effective method and low-cost waste or biomass known as bio-adsorbents [8]. Cellulosic materials are among the good candidates to be used as bio-adsorbents. However, cellulose itself has low sorption capacities, therefore, chemical modification is essential to enhance its sorption capability as an efficient adsorbent [9]. 
The free radical polymerization method is widely used to produce the grafting copolymers with various cellulose materials. Thus, free radicals can be formed by initiators such as ceric ammonium nitrate (CAN) as an oxidizing agent, or via irradiation with gamma rays or ultraviolet rays. Certainly, the radicals are generated on the cellulose (AGU, anhydroglucose unit) resulting covalent bonds formed with the desired monomers, further in many propagating units are growing until termination process occurs. Ultimately, a grafting copolymer product can be generated via disproportionation step or combination of two growing cellulose molecules [10-12]. Subsequently, chemical modification of the grafted cellulose using various reactions offer suitable chelating ligands for the coordination with metals ions. In general, a coordination compound is actually composed of atoms, molecules or small groups of atoms that contain electrical charges which are usually negatively charged or neutral charge, that are attached to a central metal atom [13].

In this report, pure cellulose is extracted from waste jute fiber. Then the cellulose was used to grafting reaction by the free radical initiation method with two different monomers to produce the poly (methyl acrylate)-grafted cellulose (PMA-grafted cellulose) and or poly (acrylonitrile)-grafted cellulose (PAN-grafted cellulose). Further both grafted cellulose was converted into the poly (hydroxamic acid)/poly (amidoxime) ligands for removal of toxic metals from and wastewater.

\section{Materials and Methods}

\subsection{Chemicals}

Jute known as golden fiber (Tossa jute) and waste jute fiber was obtained from the jute fiber processing industry, Pansgha, Bangladesh. Other chemicals were purchase from local market.

\subsection{Extraction of Cellulose from Waste Jute Fiber}

For removing the lignin component, about $100 \mathrm{~g}$ of dry waste jute fiber was boiled with $500 \mathrm{~L}$ of $15 \%$ sodium hydroxide $(\mathrm{NaOH})$ solution and bleach with hydrogen peroxide $(50 \%)$ until the mixture become white color. Details procedure is described in the previous study $[10,14]$.

\subsection{Preparation of Poly (Methyl Acrylate)/or Acrylonitrile Grafted Jute Cellulose}

The PMA-grafted cellulose/or PAN-grafted cellulose was synthesized from the jute cellulose using free radical initial process. The methyl acrylate monomer was used for the synthesis of PMAgrafted cellulose whereas PAN-grafted cellulose was prepared from acrylonitrile monomer. For graft copolymerization, reaction conditions are described in the previous study $[10,11]$.

\subsection{Synthesis of Poly (Hydroxamic Acid) Ligand/or Poly (Amidoxime) Ligand}

The poly (hydroxamic acid) ligand (PHA) was prepared from PMA-grafted cellulose whereas poly (amidoxime) ligand (PA) was prepared from PAN-grafted cellulose by oximation reaction. For the preparation of hydroxylamine solution and reaction conditions are described elsewhere [10,11].

\subsection{Adsorption and Isotherm Study by PHA/PA Ligands}

The batch adsorption was used to study the adsorption characters of the PHA/PA ligands with four types of metal ions was selected at different $\mathrm{pH}$ from 3-6. The concentration of metal ions ranging from 10 to $1800 \mathrm{ppm}$ was used for isotherm study in the previous study [11]. The ICP-OES was used to measure the initial and final concentration of the metals by the Equation (1) [12].

$$
\mathrm{q}_{\mathrm{e}}=\frac{\left(\mathrm{C}_{\mathrm{o}}-\mathrm{C}_{\mathrm{e}}\right) \mathrm{V}}{\mathrm{m}}
$$

where $\mathrm{q}_{\mathrm{e}}$ stand for adsorption capacity $\left(\mathrm{mg} \mathrm{g}^{-1}\right)$. Here $\mathrm{C}_{\mathrm{o}}$ and $\mathrm{C}_{\mathrm{e}}$ are the initial and the final concentration of the metal ions ( $\mathrm{mg} \mathrm{L}^{-1}$ ) in solution, respectively. $\mathrm{V}$ and $\mathrm{m}$ are referred to the volume (L) and the mass of the adsorbent (g), respectively. 


\section{Results and Discussion}

\subsection{Reaction Mechanism}

The most conventional method to carry out graft copolymerization is by free radical polymerization process. It is a reaction involving the presence of radicals, it is a chain reaction process, consisting initiation, propagation and termination [10]. An initiator is required to initiate the chain reaction. For graft copolymerization, free radicals can be formed by initiators on the cellulose structure and subsequently reaction with vinyl or acrylic monomers [12]. The free radicals bearing D-glucose units then added with acrylic monomers and further initiated the free radical on the cellulosic backbone for propagation reaction resulting in the grafting copolymer products. The graft copolymerization of cellulose with methyl acrylate/or acrylonitrile initiated with the ceric ions as a free-radical chain reaction. The ceric (IV) ions and created a complex of the D-glucose units, and the hydrogen atom is oxidized by the reduction of the $\mathrm{Ce}^{4+}$ to $\mathrm{Ce}^{3+}$ ions. Thus, the free-radicals on the cellulose cause the initiation of the double bonds in the monomer's, subsequent propagation and termination reaction have been accomplished, reaction is reported at our early work [11,14].

In this report, two types of monomers as such the methyl acrylate (MA) and acrylonitrile (AN) were used separately for jute cellulose grafting process according to the methods reported in our earlier papers [11,12]. The PMA-grafted cellulose/or PAN-grafted cellulose were then converted to chelating ligands such as the poly (hydroxamic acid) ligand (PHA)/or poly(amidoxime) ligand (PA), respectively. Both the chelating ligands were synthesized from their respective grafted copolymers, using hydroxylamine hydrochloride and methanolic solution. The chemical conversion was carried out under reported optimum conditions such as $\mathrm{pH} 10$ and temperature is $70{ }^{\circ} \mathrm{C}$ for $4 \mathrm{~h}$ [14]. As expected, the structure of PHA and PA chelating ligands shown in Scheme 1. These PHA/PA chelating ligand adsorbed metal ions to form PHA-complex or PA-complex as shown in Scheme 1.

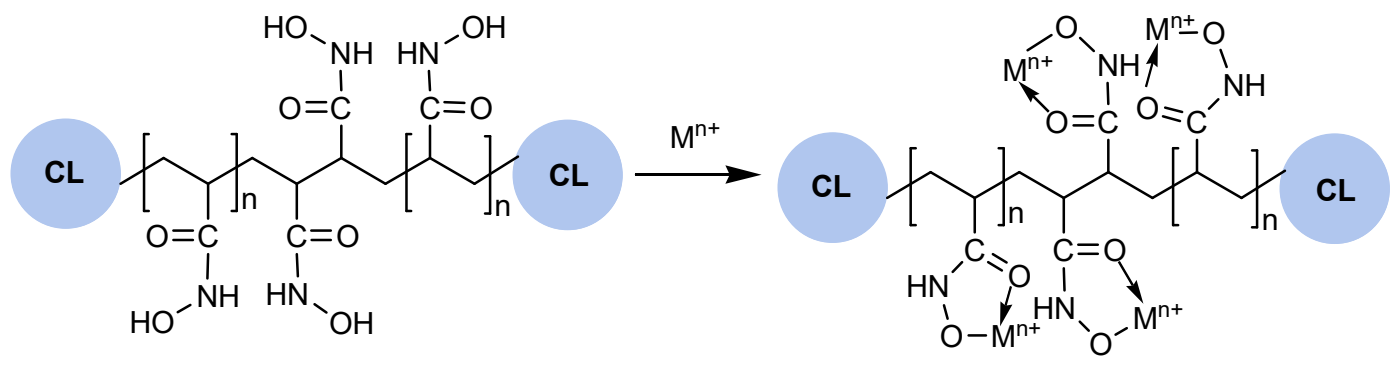

Poly(hydroxamic acid)

Poly(hydroxamic acid)-metal complex

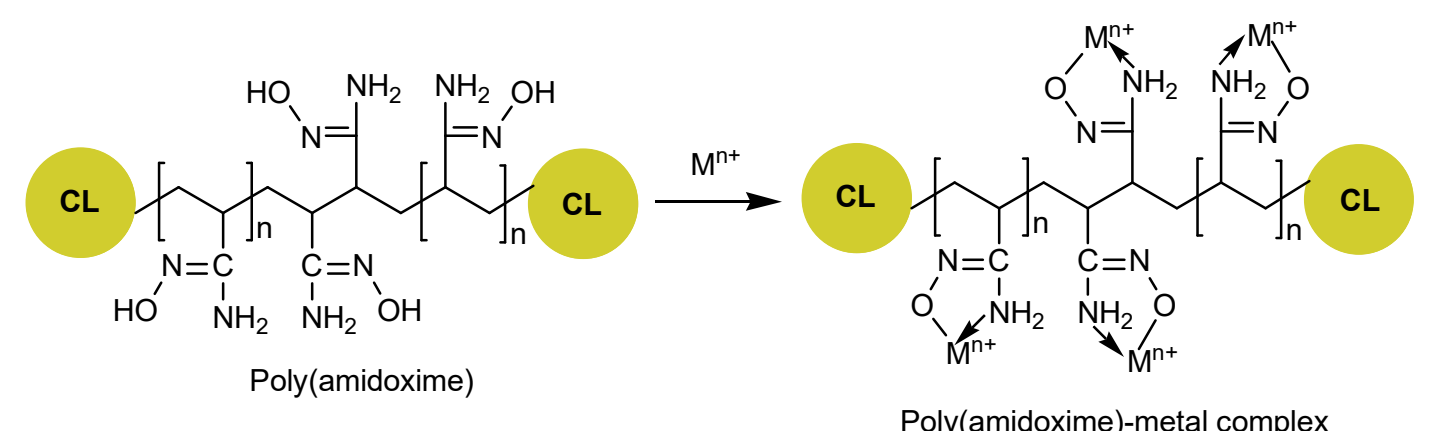

where, CL stand glucose unit and R stands either COOMe or CN

Scheme 1. Poly (hydroxamic acid), poly (amidoxime) and PHA/or PA-metal complex.

\subsection{FT-IR Spectroscopy Analysis}

FT-IR spectrum of jute cellulose is shown in Figure 1a. The presence of $\mathrm{C}_{1}-\mathrm{H}$ deformation of glycosidic linkage in the cellulose structure that a small peak is observed at $1026 \mathrm{~cm}^{-1}$ and a broad absorption band at $1152 \mathrm{~cm}^{-1}$, which is the vibration of C-O-C pyranose ring of a cellulosic structure [14]. Besides, a small peak is visible at $1258 \mathrm{~cm}^{-1}$ is assigned to the stretching of CO and $1426 \mathrm{~cm}^{-1}$ 
representing a deformation vibration for $\mathrm{CH}_{2}$ in the AGU structure, in addition a bending mode also observed at $1640 \mathrm{~cm}^{-1}$ belongs to the bound water. The peaks observed at $2896 \mathrm{~cm}^{-1}$ and $3330 \mathrm{~cm}^{-1}$ corresponding to the stretching bands of C-H and O-H in the structure of cellulose, $3333 \mathrm{~cm}^{-1}$ (Figure 1a). IR spectrum of PMA-grafted cellulose is shown in Figure 1b. A new significant sharp peak at $1720 \mathrm{~cm}^{-1}$, which represent the stretching band of carbonyl $\mathrm{C}=\mathrm{O}$ groups, belongs to the methyl acrylate. In addition, two significant sharp peaks at 1450 and $926 \mathrm{~cm}^{-1}$ were found for C-H bending scissoring for $\mathrm{CH}_{2}$ and wagging for $\mathrm{CH}_{2}$, respectively. Although several new peaks found in the spectrum of PMA-grafted cellulose, other peaks belongs to the cellulose structure was retained [10].

A broad peak was found at $3115 \mathrm{~cm}^{-1}$ corresponds to the presence of $\mathrm{N}-\mathrm{H}$ stretching and $\mathrm{O}-\mathrm{H}$ bending mode at $1395 \mathrm{~cm}^{-1}$ of the spectrum of the PHA ligand is shown in Figure 1c. A significant sharp peak in the spectrum of PMA-grafted cellulose at $1720 \mathrm{~cm}^{-1}$ was vanished and there are two bands formed at $1680 \mathrm{~cm}^{-1}$ and $1650 \mathrm{~cm}^{-1}$ in the hydroxamic acid, designated to the stretching of $\mathrm{C}=\mathrm{O}$ of the amide group [12]. The notable peak was found at $2750 \mathrm{~cm}^{-1}$ for $\mathrm{O}-\mathrm{H}$ stretching which is typically hydroxamic acid functional group. This $\mathrm{O}-\mathrm{H}$ stretching is characterized by a greater magnitude due to the hydrogen bridge forms between the oxygen and hydrogen atoms [15].
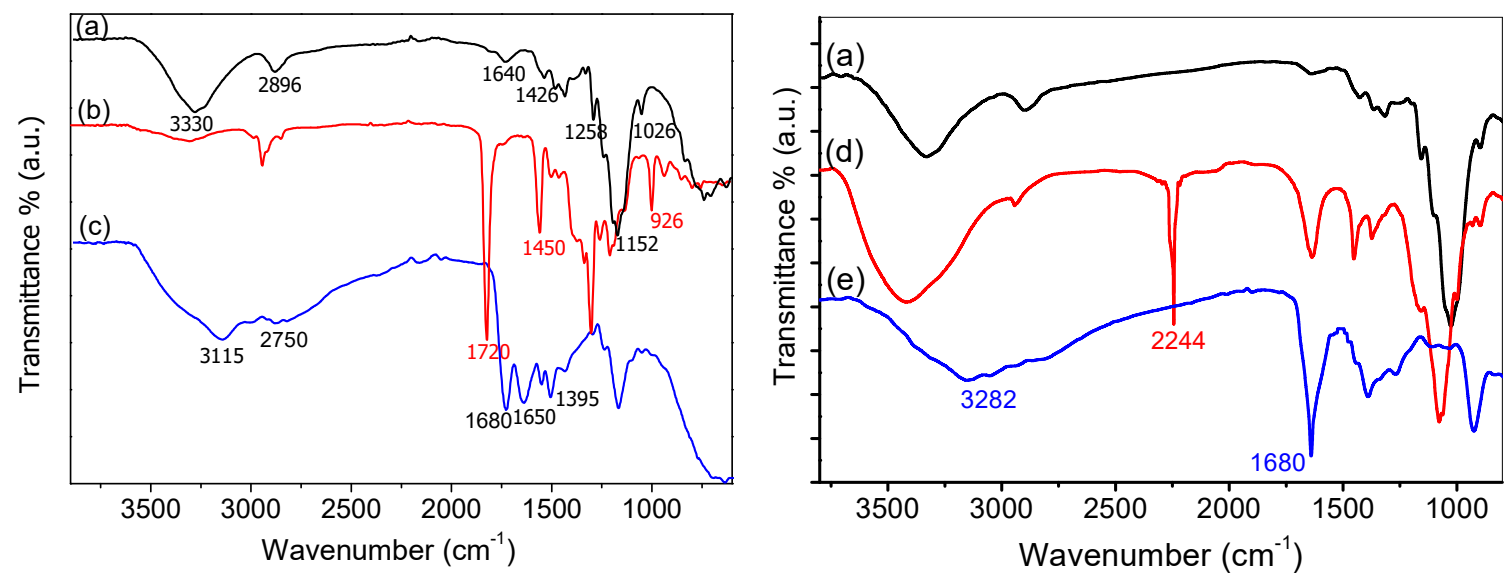

Figure 1. FTIR spectra of (left plot) jute cellulose (a), PMA-grafted cellulose (b), PHA ligand (c) and spectra of (right plot) jute cellulose (a), PAN-grafted cellulose (d), PA ligand (e).

The IR spectrum of the poly(acrylonitrile)-grafted cellulose is shown Figure 1d. A typical nitrile group a new sharp peak at $2244 \mathrm{~cm}^{-1}$ for $\mathrm{C} \equiv \mathrm{N}$ stretching was observed due to the presence of nitrile groups in the acrylonitrile functional groups. Therefore, a graft copolymer reaction was successful with the jute cellulose and other peaks were retained, which is belongs to the structure of jute cellulose [11]. In Figure 1e, a spectrum represents the PA ligand, a broadened peak found at 3282 $\mathrm{cm}^{-1}$, due to the presence of N-H stretching. A significant sharp peak in the spectrum of PAN-grafted cellulose at $2244 \mathrm{~cm}^{-1}$ was vanished and a new absorption bands at $1680 \mathrm{~cm}^{-1}$ belongs to the $\mathrm{C}=\mathrm{N}$ stretching mode, indicated the presence of amidoxime groups in the PA ligand (Figure 1e).

\subsection{FE-SEM Analysis}

Some morphological analyses were carried using FE-SEM technique with JSM-7900F (JEOL). The SEM micrograph of jute cellulose appeared a smooth wooden stick-like structure as shown in Figure 2a. The SEM micrograph of the PMA-grafted jute cellulose appeared unsmooth surface that wooden stick-like surface is abolished resulting the noticeable grafting event on the cellulosic structure as shown in Figure 2b. In Figure 2c, the SEM image of poly (hydroxamic acid) ligand showed completely different morphology compared to the grafting cellulose. The unsmooth surface of the PMA grafted cellulose was disappeared and forming unsmooth spherical beads with differing sizes as shown in Figure 2c. The spherical beads were abolished and forming a compact morphologies when PHA ligand adsorbed the copper ions as shown in Figure 2d. 

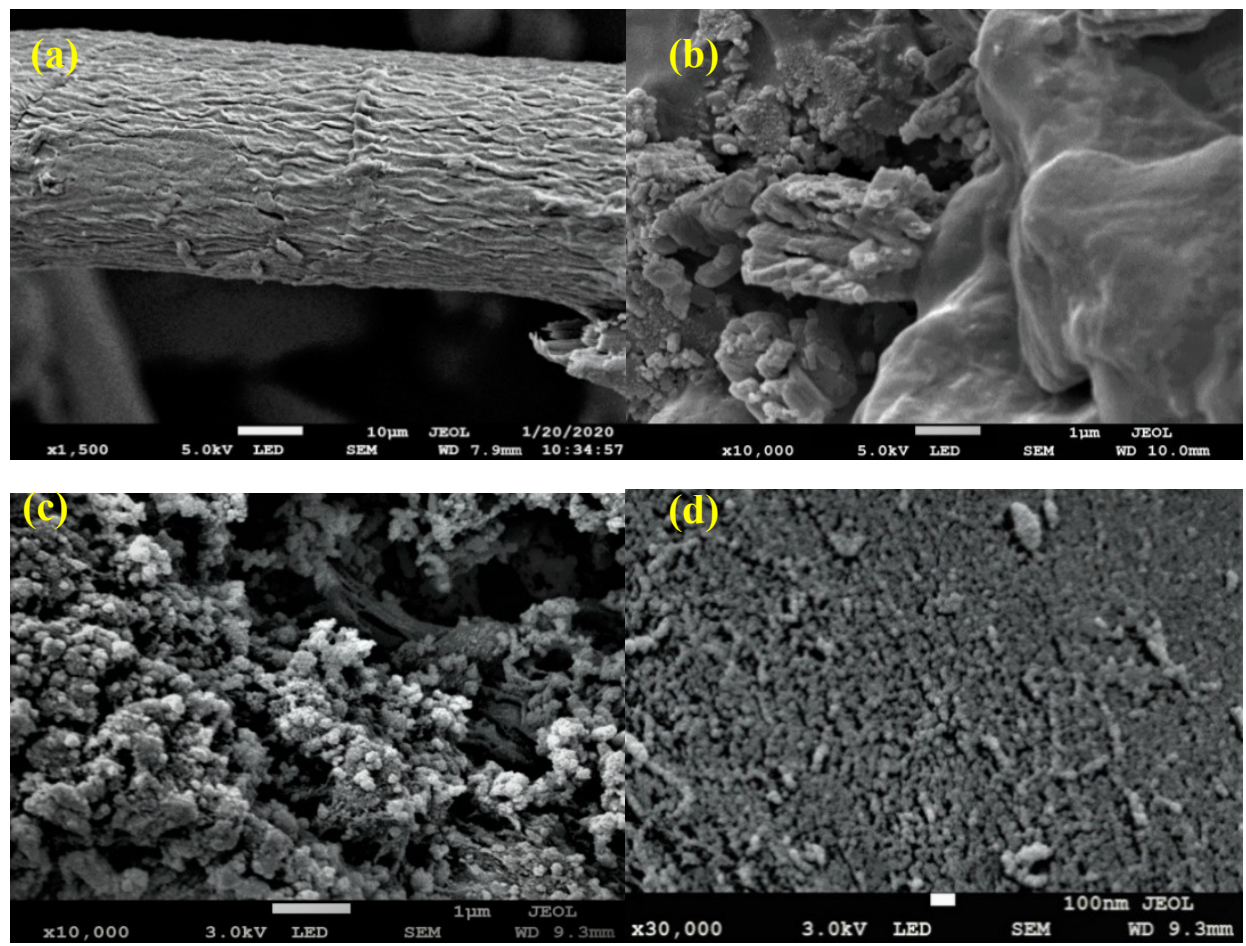

Figure 2. FE-SEM micrograph of (a) jute cellulose, (b) PMA-grafted cellulose, (c) poly (hydroxamic acid) ligand and (d) poly (hydroxamic acid) ligand-copper complex.

The same jute cellulose was used to prepared poly(acrylonitrile) grafted jute cellulose (SEM micrograph at Figure 3a is similar with Figure 2a). The SEM micrograph of the PAN-grafted cellulose showed unsmooth and rough surface morphologies, which is distinguishable with pure jute cellulose (Figure 3b). The SEM of poly(amidoxime) ligand appeared well-defined morphologies with larger size of spherical beads as shown in Figure 3c. The PA ligand showed small size of spherical beads after bind with copper ions due to shrinking of ligand surfaces (Figure 3d).

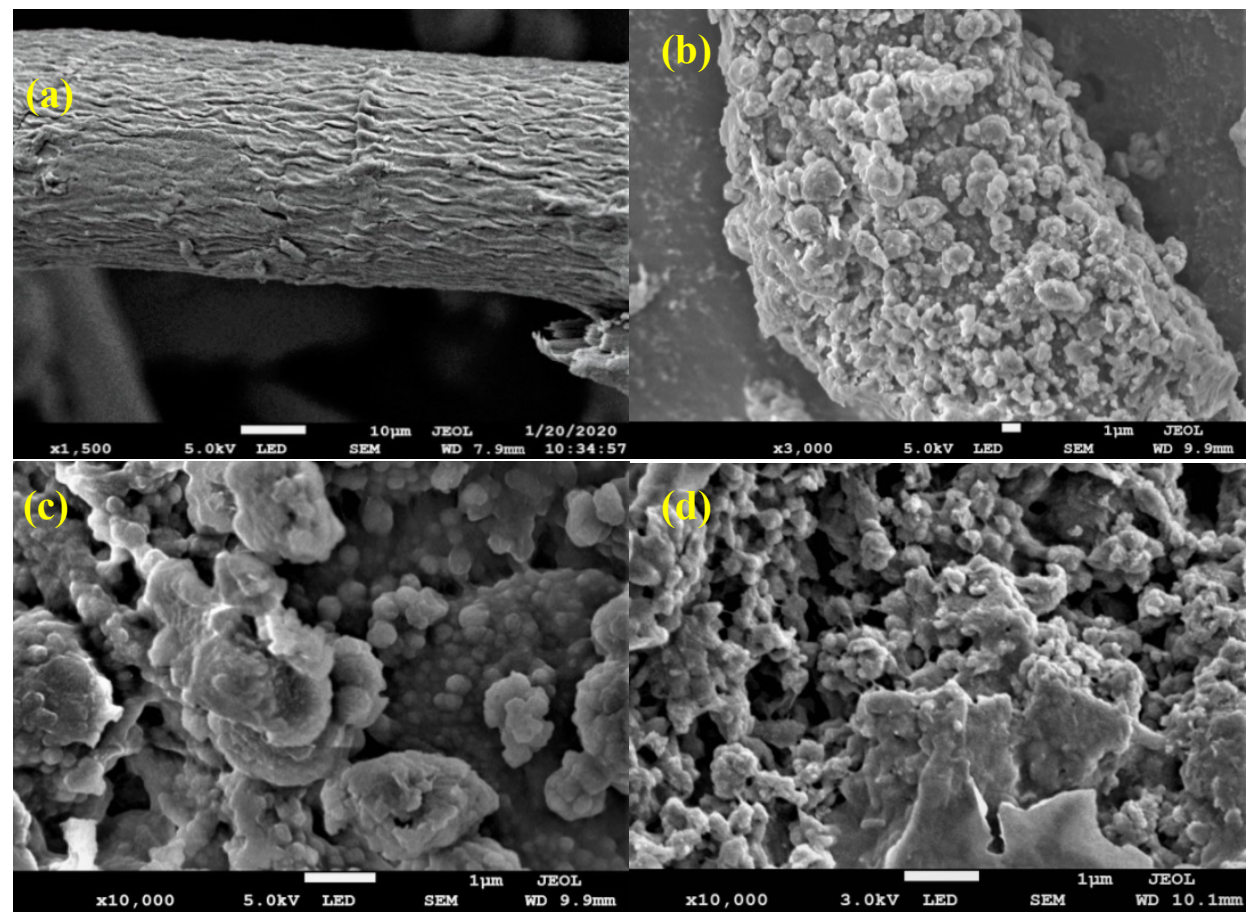

Figure 3. FE-SEM micrograph of (a) jute cellulose, (b) PAN-grafted cellulose, (c) poly (amidoxime) ligand, and (d) poly (amidoxime) ligand-copper complex. 


\subsection{Adsorption Study of Poly (Hydroxamic Acid) and Poly (Amidoxime) Ligands}

\subsubsection{Effect of $\mathrm{pH}$ on the Adsorption of Metal Ions by PHA ligand}

To find out the effect of $\mathrm{pH}$ on the adsorption behavior, four metal ions $\left(\mathrm{Cu}^{2+}, \mathrm{Co}^{2+}, \mathrm{Cr}^{3+}, \mathrm{Ni}^{2+}\right)$ were selected for the batch adsorption experiment ranging from $\mathrm{pH} 3$ to 6 . The adsorption capacity $\left(q_{e}\right)$ of toxic metal ions increased gradually from $\mathrm{pH} 3$ to 6 as shown in Figure $4 \mathrm{a}$. It was observed that $\mathrm{Cu}^{2+}$ showed the high adsorption capacity $341 \mathrm{mg} / \mathrm{g}$ at $\mathrm{pH}$. The binding capacities of $\mathrm{Co}^{2+}, \mathrm{Cr}^{3+}$, and $\mathrm{Ni}^{2+}$ were 312,225 and $180 \mathrm{mg} / \mathrm{g}$, respectively at $\mathrm{pH}$ 6. A moderate increasing of toxic metal adsorption capacities when $\mathrm{pH}$ was increased from $\mathrm{pH} 3$ to $\mathrm{pH}$ 6, therefore, the uptake of toxic metal ions by the PHA ligand is $\mathrm{pH}$ dependent. The uptake of toxic metal ions by the PHA ligand caused the complexation by coordination of PHA ligand with toxic metals. The presence of bidentate hydroxamate anions formed a complex with metals ions, where two $\mathrm{O}$ atoms of the ligand functional groups bound to the metal ions to produce the five-member ring chelates [10]. It is established principle that metal ion binding event is take place by deprotonation of the $\mathrm{OH}$ group on the hydroxamic acids chelator, and following $(\mathrm{O}, \mathrm{O})$ coordination happen between the metals certainly transition metals and the oxygen $(\mathrm{C}=\mathrm{O})$ and deprotonated $\mathrm{OH}$ group [16].

\subsubsection{Effect of $\mathrm{pH}$ on the Adsorption of Metal Ions by PA ligand}

On the other hand, a similar batch adsorption study was performed by PA ligand as shown Figure $4 \mathrm{~b}$. The results showed that $\mathrm{Cu}^{2+}$ adsorption was highest, $302 \mathrm{mg} / \mathrm{g}$ at $\mathrm{pH}$. The binding capacities of $\mathrm{CO}^{2+}, \mathrm{Cr}^{3+}$, and $\mathrm{Ni}^{2+}$ were 290,222 and $172 \mathrm{mg} / \mathrm{g}$, respectively at $\mathrm{pH}$ 6. The uptake of toxic metal ions by the PA ligand was also $\mathrm{pH}$ dependent. The presence of bidentate amidoxime chelate formed five-membered ring complexes, where two nitrogen atoms bound to the toxic metal ions to produce the chelates [10]. The same event occurred in the hydroxamic acid can be observed for amidoxime ligand resulted in at optimum $\mathrm{pH}$ conditions ( $\mathrm{pH}$ 5-6).
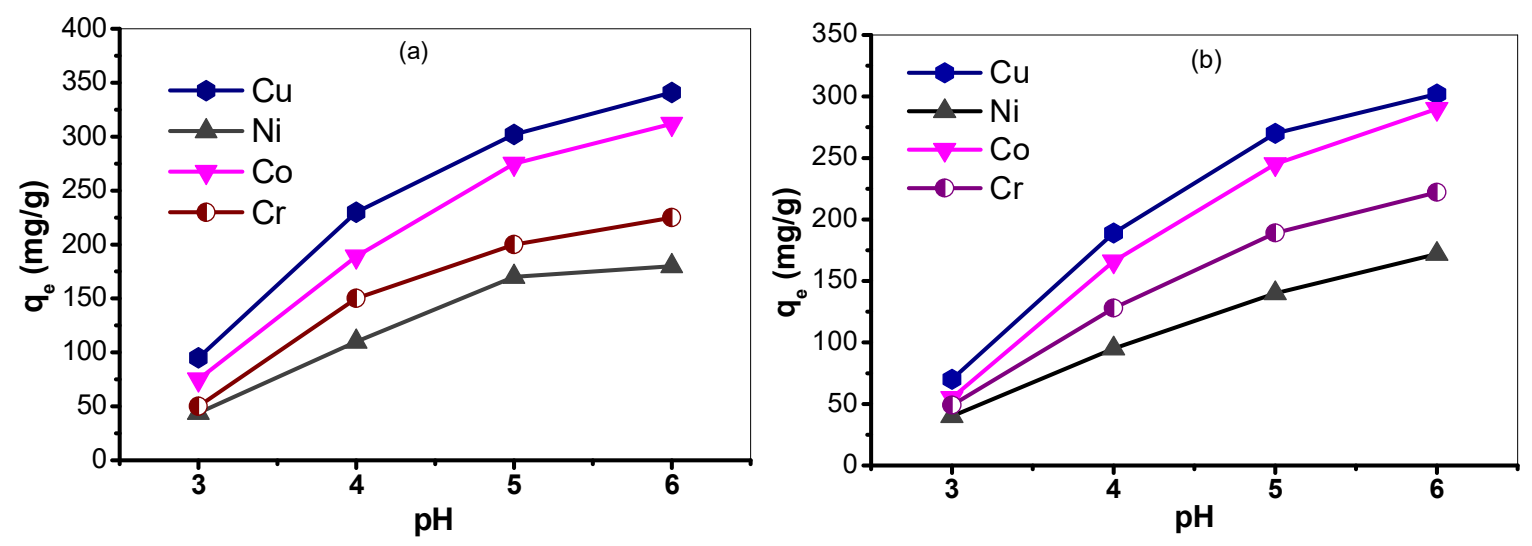

Figure 4. The effect of $\mathrm{pH}$ on the adsorption of toxic metal ions by the jute cellulose-based polymer ligands: (a) represent PHA (left graph) and (b) represent PA ligand (right graph); experimental variables: $0.5 \mathrm{~g}$ of ligand (PHA or PA), $15 \mathrm{~mL}$ of distilled water, $5 \mathrm{~mL}$ sodium acetate buffer solution at $\mathrm{pH} 3-6,5 \mathrm{~mL}$ of $0.2 \mathrm{M}$ metals solution and stirred for $2 \mathrm{~h}$.

\subsection{Sorption Isotherm}

\subsubsection{Linear Langmuir Adsorption Isotherm}

The adsorption system in Langmuir adsorption isotherm model fits with several criteria, including it involve a single layer or monolayer adsorption, which means the adsorption occurs only on the surface of the adsorbate [17]. The linear form of Langmuir adsorption isotherm model is shown in the following Equation (2) [17]: 


$$
\frac{C_{e}}{q_{e}}=\frac{1}{q_{\max } K_{L}}+\frac{C_{e}}{q_{\max }}
$$

As referred to the Equation (2), qe stand for the equilibrium adsorption capacity (mg/g), $C_{e}$ is the equilibrium concentration of toxic metal ions in their respective aqueous solutions $(\mathrm{mg} / \mathrm{L}), \mathrm{q}_{\max }$ and $\mathrm{K}_{\mathrm{L}}$ stands for the maximum capacity $(\mathrm{mg} / \mathrm{g})$ and Langmuir adsorption constant $(\mathrm{L} / \mathrm{g})$, respectively.

By applying the Equation (2), all the values of qmax for toxic metal ion were determined from the slopes or gradients of the line graphs, while all the values of $\mathrm{K}_{\mathrm{L}}$ for each toxic metal ion were calculated based on the intercepts obtained from the line graphs in the linear plots of $\mathrm{C}_{\mathrm{e}} / \mathrm{q}_{\mathrm{e}}$ against $\mathrm{C}_{\mathrm{e}}$ as shown in Figure $5 \mathrm{a}$ for PHA ligand and Figure $5 \mathrm{~b}$ for PA ligand. The data presented in Table 1, it can be observed that all the values of correlation coefficient $\left(R^{2}\right)$ can be accepted, $R^{2}>0.98$. However, the calculated results (Table 1), the adsorption capacity values calculated from Langmuir model have significant difference with the experimental adsorption capacities, qe. Thus the single or monolayer adsorption of toxic metal ions seems to be not occurred on the surface of the PHA/PA ligands.
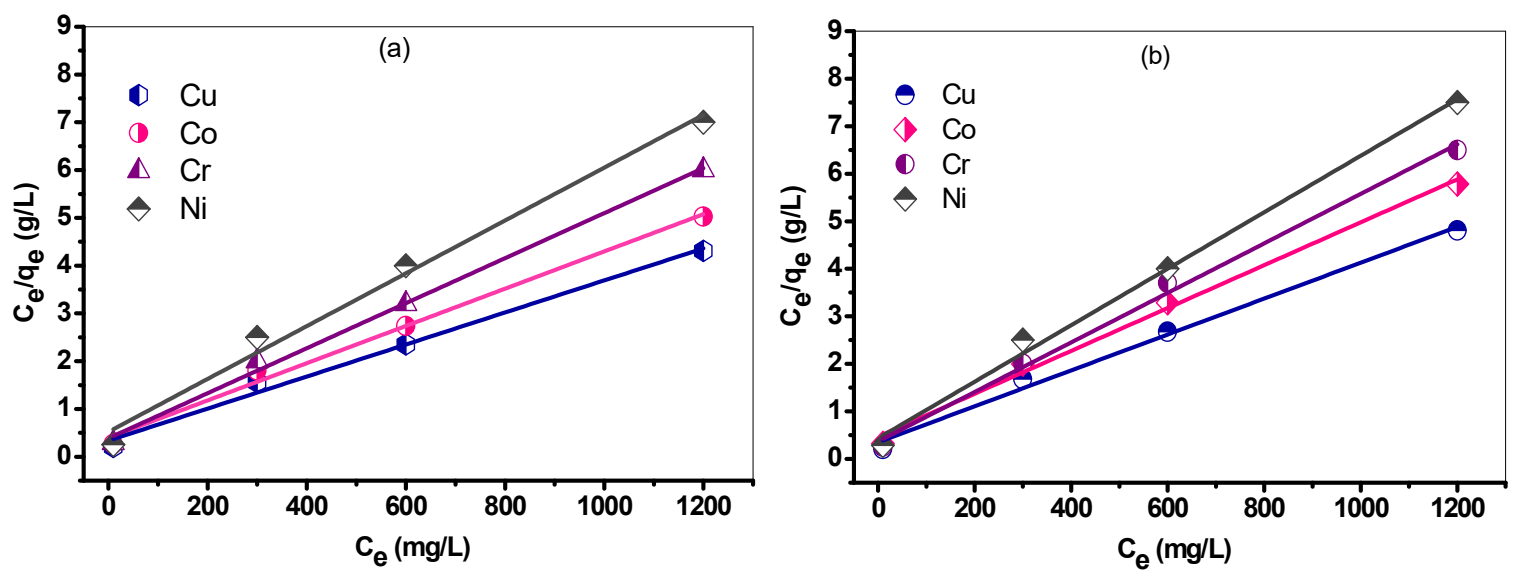

Figure 5. Langmuir isotherm curves obtained by linear fitting on the adsorption of metal ions metal by the jute cellulose-based polymer ligands: (a) represent PHA and (b) represent PA ligand; experimental variables: $0.5 \mathrm{~g}$ of ligands (PHA or PA), $15 \mathrm{~mL}$ of distilled water, $5 \mathrm{~mL}$ of $\mathrm{pH} 6 \mathrm{buffer}$ solution, $5 \mathrm{~mL}$ of $0.2 \mathrm{M}$ synthetic metals ions solution and stirred for $2 \mathrm{~h}$.

Table 1. The linear form of Langmuir isotherm parameters for polymer adsorbent, PHA/PA.

\begin{tabular}{ccccccc}
\hline \multirow{2}{*}{ Adsorbent } & Adsorbate & \multicolumn{3}{c}{ Langmuir } & Experimental \\
\cline { 3 - 6 } & & $\mathbf{q}_{\mathbf{m a x}} \mathbf{( m g / g )}$ & $\mathbf{K}_{\mathbf{L}} \mathbf{( L / g )}$ & $\mathbf{R}^{\mathbf{2}}$ & $\begin{array}{c}\text { Difference } \\
\mathbf{( m g} / \mathbf{g})\end{array}$ \\
\hline \multirow{3}{*}{$\mathrm{PHA}$} & $\mathrm{Cu}$ & 302 & 0.00039 & 0.980 & 341 & 39 \\
& $\mathrm{Co}$ & 260 & 0.00032 & 0.985 & 312 & 52 \\
& $\mathrm{Cr}$ & 194 & 0.00048 & 0.986 & 225 & 31 \\
& $\mathrm{Ni}$ & 142 & 0.00045 & 0.982 & 180 & 38 \\
\hline \multirow{3}{*}{$\mathrm{PA}$} & $\mathrm{Cu}$ & 262 & 0.00038 & 0.989 & 302 & 40 \\
& $\mathrm{Co}$ & 230 & 0.00041 & 0.986 & 290 & 60 \\
& $\mathrm{Cr}$ & 167 & 0.00035 & 0.984 & 222 & 55 \\
& $\mathrm{Ni}$ & 145 & 0.00045 & 0.982 & 172 & 27 \\
\hline
\end{tabular}

\subsubsection{Linear Freundlich Adsorption Isotherm}

According to the assumptions by Freundlich adsorption isotherm model is the multiple layer adsorption, whereby the surface of the adsorbent (polymeric ligand) is heterogenous [18]. A linear Freundlich isotherm is expressed by Equation (3) [18].

$$
\log q_{e}=\log K_{F}+\frac{\log C_{e}}{n}
$$


Based on the Equation (3), qe stand for equilibrium adsorption capacity on the PHA/PA ligands, $\mathrm{C}_{\mathrm{e}}$ is the equilibrium concentration $(\mathrm{mg} / \mathrm{L}), \mathrm{K}_{\mathrm{F}}$ is Freundlich's constant $(\mathrm{L} / \mathrm{mg})$, and $1 / \mathrm{n}$ is the heterogeneity factor that relates to the adsorption capacity.

By applying the Equation (3), the values of $\mathrm{n}$ for every toxic metal ion were determined from the slopes or gradients of the line graphs, while all the values of $\mathrm{K}_{\mathrm{F}}$ for each toxic metal ion were calculated based on the intercepts obtained from the line graphs in the linear plots of log qe against $\log C_{e}$ as shown in Figure 6a for PHA ligand and Figure $6 \mathrm{~b}$ for PA ligand. The data obtained in Table 2 , the overall the values of correlation coefficient were significant, where $\mathrm{R}^{2}<0.99$. By making comparison with the results in Langmuir adsorption isotherm, it can be observed that the correlation coefficient $\mathrm{R}^{2}$ values in Freundlich isotherm were more fit compared to the Langmuir isotherm, indicating Freundlich adsorption was more predominant compared to Langmuir isotherm. Thus, it indicated that it was likely to have multilayer adsorption of toxic metal ions occurred on the heterogeneous surface of the PHA/PA ligands [18].
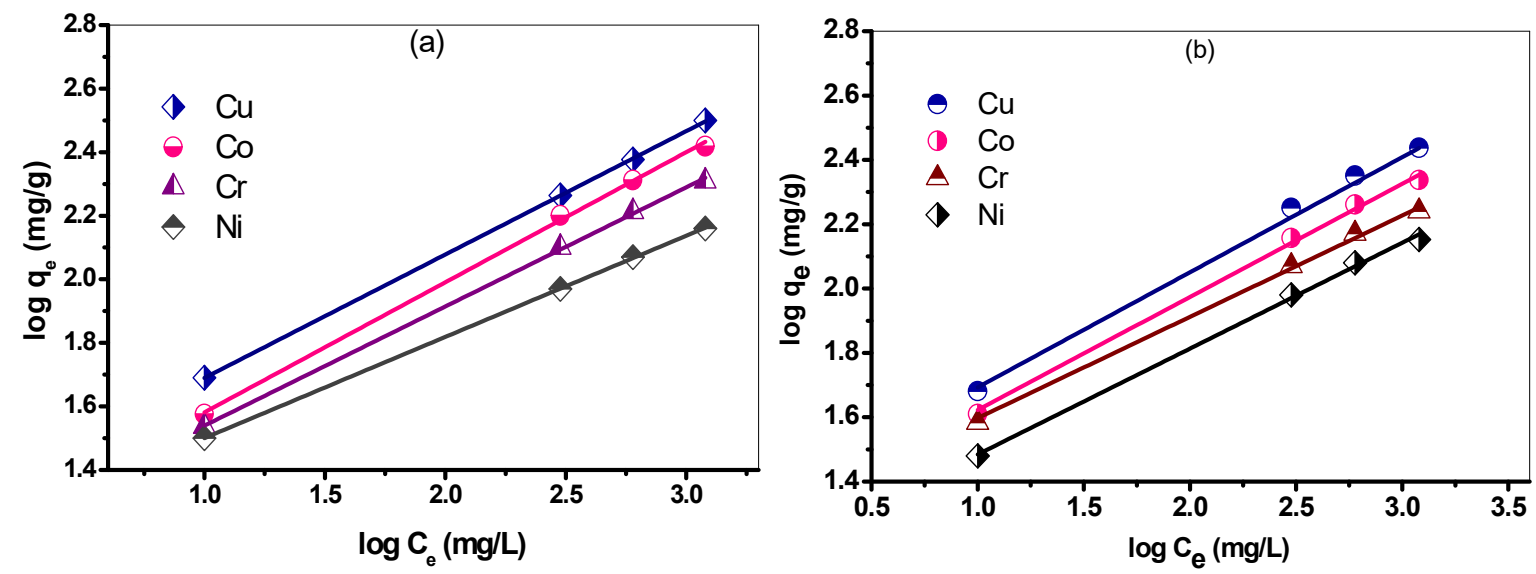

Figure 6. Freundlich isotherm curves obtained by linear fitting on the adsorption of metal ions metal by the jute cellulose-based polymer ligands: (a) represent PHA and (b) represent PA ligand; experimental variables: $0.5 \mathrm{~g}$ of ligands (PHA or PA), $15 \mathrm{~mL}$ distilled water, $5 \mathrm{~mL}$ pH 6 buffer solution, $5 \mathrm{~mL}$ of $0.2 \mathrm{M}$ synthetic metals ions solution and stirred for $2 \mathrm{~h}$.

Table 2. Freundlich isotherm parameters for polymer adsorbent, PHA/PA.

\begin{tabular}{ccccc}
\hline \multirow{2}{*}{ Adsorbent } & \multirow{2}{*}{ Adsorbate } & \multicolumn{3}{c}{ Freundlich } \\
\cline { 3 - 5 } & & $\mathbf{1 / n}$ & $\mathbf{K L}(\mathbf{L} / \mathbf{m g})$ & $\mathbf{R}^{\mathbf{2}}$ \\
\hline \multirow{3}{*}{ PHA } & $\mathrm{Cu}$ & 1.23 & 0.368 & 0.999 \\
& $\mathrm{Co}$ & 1.28 & 0.407 & 0.998 \\
& $\mathrm{Cr}$ & 1.26 & 0.362 & 0.999 \\
& $\mathrm{Ni}$ & 1.22 & 0.287 & 0.999 \\
\hline \multirow{3}{*}{ PA } & $\mathrm{Cu}$ & 1.31 & 0.369 & 0.998 \\
& $\mathrm{Co}$ & 1.12 & 0.414 & 0.997 \\
& $\mathrm{Cr}$ & 1.20 & 0.304 & 0.999 \\
& $\mathrm{Ni}$ & 1.22 & 0.309 & 0.998 \\
\hline
\end{tabular}

\subsection{Electroplating Wastewater Purification}

Practical Application of PHA ligand

For a real-life practical application, Table 3 showed the results obtained for the concentrations (before ligands treatment and after ligands treatment) by using ICP-MS. The industrial wastewater sample was collected from a semiconductor metal plating workshop that performing PCB etching (Porcel, Singapore). In Table 3, it can be seen that the removal of toxic toxic metal ions were effective and significant. For PHA ligand, the removal efficiency of $\mathrm{Cu}^{2+}$ and $\mathrm{Fe}^{3+}$ was higher more than $98 \%$. 
While removal of $\mathrm{Pb}^{2+}, \mathrm{Cr}^{3+}, \mathrm{Mn}^{2+}$ and $\mathrm{Ni}^{2}$ was also more than $90 \%$. For PA ligand, the removal efficiency of toxic metal ions of $\mathrm{Cu}^{2+}$ was higher more than $98 \%$. Other toxic metal ions also show removal efficiency more than $90 \%$. Overall, it was found that the highly effective removal of toxic metal ions by PHA/PA ligands. Other metal ions were also detected in both the industrial wastewater sample they have shown lower removal efficacies due to the nature of hydroxamic acid chelating ligand does not selective for alkali metals.

Table 3. Compositions of metal ions into industrial wastewater sample before and after treatment by PHA/PA ligands.

\begin{tabular}{ccccccc}
\hline \multirow{2}{*}{$\begin{array}{c}\text { Metal } \\
\text { Ions }\end{array}$} & $\begin{array}{c}\text { Before } \\
\text { Treatment } \\
(\mathbf{p p m})\end{array}$ & $\begin{array}{c}\text { PHA ligand } \\
\text { Treatment } \\
(\mathbf{p p m})\end{array}$ & $\begin{array}{c}\text { \% } \\
\text { Removal }\end{array}$ & $\begin{array}{c}\text { Before } \\
\text { Treatment } \\
(\mathbf{p p m})\end{array}$ & $\begin{array}{c}\text { PAfter } \\
\text { Treatment } \\
(\mathbf{p p m})\end{array}$ & $\begin{array}{c}\text { ligand } \\
\text { Removal }\end{array}$ \\
\hline $\mathrm{Fe}^{3+}$ & 32.0095 & 0.5692 & 98.22 & 1.4637 & 0.0221 & 98.49 \\
$\mathrm{Cu}^{2+}$ & 23.0493 & 0.4512 & 98.04 & 85.7627 & 1.689 & 98.03 \\
$\mathrm{~Pb}^{2+}$ & 0.0207 & 0.003 & 85.50 & 0.1331 & 0.0166 & 87.52 \\
$\mathrm{Zn}^{2+}$ & 0.0421 & 0.008 & 80.99 & 0.1037 & 0.0093 & 91.03 \\
$\mathrm{Cr}^{3+}$ & 0.0268 & 0.0012 & 95.52 & 0.0857 & 0.0037 & 95.68 \\
$\mathrm{Mn}^{2+}$ & 0.1296 & 0.0103 & 92.05 & 0.0055 & 0.0014 & 74.54 \\
$\mathrm{Ni}^{2+}$ & 0.0182 & 0.0015 & 91.75 & 0.4421 & 0.0372 & 91.58 \\
$\mathrm{Ca}^{2+}$ & 0.5517 & 0.41269 & 25.19 & 0.8918 & 0.66335 & 25.61 \\
$\mathrm{~K}^{+}$ & 0.0783 & 0.0589 & 24.77 & 0.2791 & 0.2231 & 20.06 \\
$\mathrm{Na}^{+}$ & 15.2312 & 11.2369 & 26.22 & 9.7411 & 8.1234 & 16.60 \\
$\mathrm{Mg}^{2+}$ & - & - & & 0.0879 & 0.0623 & 29.12 \\
\hline
\end{tabular}

\section{Conclusions}

The cellulose was extracted from waste jute fiber and further chemical modification was performed to obtained polymeric chelating ligands for enable to toxic metal recovery from wastewater. The synthesized PHA and PA ligands were characterized by batch adsorption study with several toxic metal ions and also practical applications of synthesized ligands were determined. The Freundlich isotherm showed best fit to the linear isotherm model with excellent correlation coefficients for multiple layers adsorption. The both polymeric ligands showed outstanding removal efficiency from the industrial wastewater up to $98 \%$ removal of copper and other metal ions about $90 \%$ from electroplating wastewater.

Acknowledgments: This research was supported by the Universiti Malaysia Sabah grant no. SGI0061-2018.

Conflicts of Interest: The author declared no conflict of interest.

\section{References}

1. Lakherwal, D. Adsorption of Toxic Metals: A Review. Int. J. Environ. Res. Dev. 2014, 4, 41-48.

2. Gunatilake, S.K. Methods of Removing Toxic Metals for Industrial Wastewater. J. Multidiscip. Eng. Sci. Stud. 2015, 1, 12-18.

3. Mnasri-Ghnimi, S.; Frini-Srasra, N. Removal of toxic metals from aqueous solutions by adsorption using single and mixed pillared clays. Appl. Clay Sci. 2019, 179, 105151, doi:10.1016/j.clay.2019.105151

4. Zhang, Y.; Duan, X. Chemical precipitation of toxic metals from wastewater by using the synthetical magnesium hydroxy carbonate. Water Sci. Technol. 2020, 81, 1130-1136.

5. Tang, X.; Zheng, H.; Teng, H.; Sun, Y.; Guo, J.; Xie, W. Chemical coagulation process for the removal of toxic metals from water: A review. Desalination Water Treat. 2016, 57, 1733-1748.

6. Bashkim, S.T.; Salih, T.G. Reverse osmosis removal of toxic metals from wastewater effluents using biowaste materials pretreatment. Pol. J. Environ. Stud. 2019, 28, 337-341.

7. Khulbe, K.C.; Matsuura, T. Removal of toxic metals and pollutants by membrane adsorption techniques. Appl. Water Sci. 2019, 8, 19, doi:10.1007/s13201-018-0661-6

8. Suhas; Gupta, V.K.; Carrott, P.J.; Singh, R.; Chaudhary, M.; Kushwaha, S. Cellulose: A review as natural, modified and activated carbon adsorbent. Bioresour. Technol. 2016, 216, 1066. 
9. Kang, H.; Liu, R.; Huang, Y. Graft modification of cellulose: Methods, properties and applications. Polymer 2015, 70, A1-A16.

10. Rahman, M.L.; Sarkar, S.M.; Yusoff, M.M.; Abdullah, M.H. Optical detection and efficient removal of transition metal ions from water using poly (hydroxamic acid) ligand. Sens. Actuators B Chem. 2017, 242, 595-608.

11. Rahman, M.L.; Fui, C.J.; Sarjadi, M.S.; Arshad, S.E.; Musta, B.; Abdullah, M.H.; Sarkar, S.M.; O’Reilly, E.J. Poly (amidoxime) ligand derived from waste palm fiber for the removal of toxic metals from electroplating wastewater. Environ. Sci. Pollut. Res. 2020, 27, 34541-34556.

12. Rahman, M.L.; Wong, Z.J.; Sarjadi, M.S.; Abdullah, M.H.; Heffernan, M.A.; Sarkar, M.S.; O’Reilly, E. Poly (hydroxamic acid) ligand from palm-based waste materials for removal of toxic metals from electroplating wastewater. J. Appl. Polym. Sci. 2020, 138, 49671.

13. Dmitrii, S.B.; Nadezhda, A.B.; Vadim, Y.K. Coordination chemistry and metal-involving reactions of amidoximes: Relevance to the chemistry of oximes and oxime ligands. Coord. Chem. Rev. 2016, 313, 62-93.

14. Rahman, M.L.; Sarkar, S.M.; Yusoff, M.M.; Abdullah, M.H. Efficient removal of transition metal ions using poly(amidoxime) ligand from polymer grafted kenaf cellulose. RSC Adv. 2016, 6, 745-757.

15. Larkin, P.J. IR and Raman Spectra-Structure Correlations: Characteristics Group Frequencies. In IR and Raman Spectroscopy Principles and Spectral Interpretation; Elsevier: Amsterdam, The Netherlands, 2017; pp. 73-115.

16. Naciye, T. Stability of metal chelates of some hydroxamic acid ligands. J. Chem. Eng. Data 2011, 56, 23372342.

17. Swenson, H.; Stadie, N.P. Langmuir's Theory of Adsorption: A Centennial Review. Langmuir 2019, 35, 5409-5426.

18. Appel, J. Freundlich's Adsorption Isotherm. Surf. Sci. 1973, 39, 237-244.

Publisher's Note: MDPI stays neutral with regard to jurisdictional claims in published maps and institutional affiliations.

(C) 2020 by the authors. Submitted for possible open access publication under the terms and conditions of the Creative Commons Attribution (CC BY) license (http://creativecommons.org/licenses/by/4.0/). 